\title{
Bridging Digital Divides through Digital Media Buses: An action research study on digital inclusion in Sweden
}

Elin Wihlborg and J ulia Engström

The self-archived postprint version of this journal article is available at Linköping University Institutional Repository (DiVA):

http:// urn.kb.se/ resolve?urn=urn:nbn:se:liu:diva-139171

N.B.: When citing this work, cite the original publication.

Wihlborg, E., Engström, J ., (2017), Bridging Digital Divides through Digital Media Buses: An action research study on digital inclusion in Sweden, Conference fr E-Democracy and Open Government (CeDEM), 2017. https:// doi.org/ 10.1109/ CeDEM.2017.30

Original publication available at:

https:// doi.org/ 10.1109/ CeDEM.2017.30

Copyright: Institute of Electrical and Electronics Engineers (IEEE)

http:// www.ieee.org/ index.html

(C) 2017 IEEE. Personal use of this material is permitted. However, permission to reprint/republish this material for advertising or promotional purposes or for creating new collective works for resale or redistribution to servers or lists, or to reuse any copyrighted component of this work in other works must be obtained from the IEEE. 


\title{
Bridging Digital Divides through Digital Media Buses
}

\author{
An action research study on digital inclusion in Sweden
}

\author{
Elin Wihlborg \\ Professor, Department of Management and Engineering \\ Linkoping University \\ Sweden \\ elin.wihlborg@liu.se \\ Julia Engstrom \\ Master Student, Department of Management and Engineering \\ Linkoping University \\ Sweden \\ juliapaulinaengstrom@gmail.com
}

\begin{abstract}
Strategies and policies to bridge identified and potential digital divides is a core challenge when forming an inclusive and participatory digital democracy and society. In line with the progress and development of digital technologies and applications governments have to address digital divides. This project discusses how social and digital divides have been addressed in a project called "The Digital media bus in Östergötland". This project builds on the library buses that have has been running in the region for long a long time. The libraries in Sweden also have to address digital inclusion and implement strategies towards increased use of and knowledge about information technologies. This analysis builds on an action research approach. The analyse here are focusing on the implementation, project management and how the project has addressed digital inclusion. Finally, we end up discussing the diversity of digital inclusion, elaborating on the meanings of digital divides and digital diversity.
\end{abstract}

Keywords: Digital inclusion; Digital media buses; Digital divides; e-government; Sweden

\section{INTRODUCTION - INCLUDING EVERYONE IN THE DIGITAL SOCIETY}

Digital divides are a core challenge for an inclusive and participatory digital democracy and society. The concept of digital divides have developed from a focus on access to digital infrastructure [1] to include digital literacy in many different shapes comprising classical social divides $[2,3]$. The development is in line with the progress of digital technologies and applications used in many different government services and public administration. Policy makers and others are addressing new forms of digital divides. This paper focus on one such policy, the project called "Digital media bus in Östergötland" in Sweden. Here, the library buses have been used to take on the central community function of public libraries library to reach out and bridge digital divides in particular in socio-economically weak residential area.

Digitalization has in many states given public libraries a new and broader assignment to enhance and empower digital inclusion. The need to support and empower inhabitants in socio-economic weak communities, has been part of the libraries general duties. However, now they also have to address digital inclusion here. For example, public computers are often made available at libraries for use free of charge for a limited time. The new role of libraries in the digital era has been noticed and discussed in terms of access to the Internet and e-government [4]. Public libraries have played a key function in many countries to make the Internet more accessible. Already a few years after the Internet and the World Wide Web was launched, many libraries provided public computers connect to the Internet and in the mid-2000s most public libraries in the US provided free public Internet access [5]. Library buses have been in use in many countries to reach inhabitants in more peripheral area. There are examples of how library buses in the US have evolved to mobile technique labs, carrying computers, 3D printers, WiFi and other technical equipment. These buses have intended to reach disadvantaged youths that do not have digital equipment, by meeting up at established meeting places like churches and youth centres, to reach the youths in their own safe arenas [6]. In Sweden, there are 2301 public libraries serving a population of almost 10 million inhabitants. At these libraries, there are total of 14097 public computers and 1257 free WiFi areas. The libraries have almost 90 million real visits and 65 million visits to their webpages [7]. In this paper, we will present a case study of one such initiative that has taken the form of an action research project in the region of Östergötland and further analyse the implications in relation to the conceptualisation of digital divides. 


\section{A. Aim and research questions}

This paper aims to analyse a case study of how digital media buses can bridge digital divides to make the society more inclusive.

Three overall research questions are guiding the paper:

- RQ1: How are digital divides conceptualized in research and policy practice, in general and in a Swedish context in particular?

- RQ2: What was going on in the local project "The Digital Media bus in Östergötland" and how was the project addressing issues of digital divides?

- RQ3: What lessons can be learned on the meanings of digital diversity through the case study?

\section{B. Outline of the paper}

This paper proceeds in five main sections. Firstly, we will present and discuss the action research oriented approach that has guided the research design of this project. Secondly, we will give a brief overview of the conceptualization of digital divides. Thirdly, as the main part of the paper, we present the case study of Digital media bus. Fourthly, we analyse the case study by focusing on critical aspects of digital divides. Finally, we discuss more general implications drawn from the case study.

\section{RESEARCH DESIGN AND METHODS}

This paper aims to elaborate on the meanings of digital divides to launch and open for a more norm critical approach building on social differences and inequalities [3, 8]. Thus, the research presented here includes both conceptual parts and an action research oriented case study [9]. In this section, we firstly present the three layers of our case study since it has been used inductively for the conceptual part of the paper. The research design of an action research oriented project is seldom planned but rather a journey through ideas and more or less practical adventures and unforeseen occasions providing analytical implications [10] thus we have to tell the story of how the project has happened and how our ethnographic field work has been co-constructed in interplay with the local actors [11]. In total this case study consists of a core of five participatory observations (with in total 75 participants), eight project meetings, one study trip, and a final focus group seminar summing it all up and discussing the implications and further activities. None of the meetings have been tape-recorded or filmed. Instead we have made detailed field notes and these have been circulated after the meetings among the professional participants and they have added to and commented on these notes. All these notes were taken in Swedish and have been translated and slightly edited for the analysis presented here.

\section{A. Action research in action}

The project has emerged through an established collaboration between the university and the region and municipalities. We have collaborated on their Regional Digital Agenda, also focusing on digital inclusion. Thus, when there was an opening to apply for funding from the national innovation agency Vinnova, we formed a project building on an action research approach. The regional library had to be the main applicant of the project, due to the call. The function of research was subordinated, but critical for the funding since a project, in this specific call, had to be both informed by research and continuously evaluated. After a first workshop at Vinnova, the coordinators from the regional library and the county council were asked to make the project more innovative. At a local workshop including researchers from design studies and public administration we launched the idea of a digital media bus aiming to develop the library buses that were in use in the three largest municipalities in the region.

The application for funding focused on the potential design and equipment of a media bus in the region of Östergötland. The application was funded by Vinnova for 15 months and co-funded by the municipalities in the region, the region, and the university. The participating municipalities were Norrköping, Linköping, and Motala. The aim of the project was to conduct a pre-study of how a digital media bus could be designed and equipped. The project has been followed through an ethnographic approach.

\section{B. Designing a media bus for digital inclusion}

The project has been managed by a project leader at the regional library. There have been project groups at each of the libraries in the three participating municipalities. In Motala the issue of a new library bus had been discussed for a few years, both among the librarians and at the highest political level. It was even on the agenda for the municipal budget and had been discussed in the municipality committee. In Norrköping there were a high interest in digital inclusion, among both politicians and among the professionals at the library, and the project were there extended, as described below. In Linköping, however, the organization at the library at that moment was quite unclear and it constrained the possibilities to participate in and contribute to this project. Thus, the material for this analysis is mainly generated from the field studies in Norrköping. Impressions from the two other municipalities are not analysed in detail, but rather used for additional analyses and reflections. 
In total eight project meetings, have been held, where ideas on design and development have been discussed. The project meetings have focused on sharing ideas and experiences, mainly from Motala and Norrköping municipalities. We, as researchers, participated in all the meetings and have taken notes in different ways. At some of the meetings we had short lectures on digital inclusion, e-government, and on national policies and investigations on related issues. One of the project meetings focused on a design method called 'customer journey' [12], also the notes from this workshop has been included in the analysis. However, at the stage of analysis we learned that it would have been good to film situations like this to be able to back a reanalyse it more in-depth.

A key activity for the project was a study trip to the region of Gävleborg, where a less digitalized media bus was in use. This was a two-day trip in a rented conference bus. During the journey, approximately six hours each way, we held workshops related to the customer journey, personas on visitors to the bus and on how to support reading (a more general ambition and interest among the librarians). The trip included a visit to the library, the library bus, and a library/media centre located in the municipal House of Culture. From this trip, we have extensive field notes and reflections made by the participants. These notes have also been summarized in a short report that has been circulated among the participants and some of them made additional comments.

An additional aspect of the project was the participation of the regional chairperson of the Swedish Disability Federation. She has been contributing with issues of interests for their members. Common comments, from this perspective, hav focused on issues like space for a wheelchair on the bus, guidance for blind persons, and access to places where the bus is supposed to stop. These comments were relevant for the customer journey workshop, but less applicable in the more general discussions on what a media bus could include. Thus, we have few notes in our field notes on this perspective and it was not highlighted in the tests in Norrköping.

The municipality of Norrköping, is facing the most challenging socio-economic situation in the region both in respect of immigrants and economic development, decided to level up the project in relation to the digital media bus. In addition to the pre-study of design implication funded by Vinnova, the municipality also decided to fund extra trips with their library bus during five weekends, when it is usually not in use. For these occasions the bus was also equipped with additional "new" technological applications like MakeyMakey and other applications to reach out to children. We made participatory observations at these trips and interviewed the librarians working on the bus at these occasions before and after the test period.

This research approach has made us as researcher also a part of the project we have been studying. We have through the project contributed to its development and we have also supported the basic idea of striving towards a more inclusive way of providing e-government services in our region. However, the analysis and discussion of the implication below are stretching beyond the project and thus it is our own analysis.

\section{DIGITAL DIVIDES - A PRACTICAL PROBLEM AND A RESEARCH FIELD}

Digital divide is a concept used both in academic analyses and policy making, it was introduced by Pippa Norris in the late 1990's [1]. Since then the concept has been discussed and challenged both in research and policy practices. Thus, the concept today has several meanings and implications. It is also both used as an analytical and political concept. Even if there are statements today that digital divides have become less significant when the Internet penetration has increased [13], we will argue later that there are new challenges opening for new divides. This indicates that political and scientific meanings of digital divide are intervened.

It is obvious that digital divides are continuously re-produced and re-framed. In contemporary settings when broadband and WiFi are more accessible and smart phones are becoming a default access to digital services there are new divides emerging. There are still wide differences in the technical accessibility and increased diversity of digital literacy. These differences have in research shown to be in line with other socio-economic parameters as income, education and also age [14, p. 64]. The public libraries, as institutions, have long had the role of a cultural mediator and work for increased public education. The libraries thus provide several digitalized resources and information sources. They thus often get an assignment to promote the users' competences and improve knowledge needed to be a part of the digital society [14, p. 14]. At the same time as the public sector are moving towards an e-government, where the application for childcare or where medical prescriptions are sent over the Internet, a new and extremely important role has been given to the library where they have got a responsibility to ensure that all inhabitants have access to, the use of public administration services, and information [15, p. 39].

In this case study, it became obvious there is a need to avoid seeing citizens as a homogenous group. Such an approach is emerging in the field of e-government. It is a key to understand the digital divides in the access to and the use of public digital services $[8,16]$. In societies with social and economic divides these will be re-produced also into digital settings. A basic condition is that economic differences give different access to new technology, also geographical distance and rurality is such a clear basic divide [13]. However, there are also more complex interactions in the usage of digital tools and services that goes beyond access to technology [17].

There is a need to address digital divides as more than the access to technology and here libraries have been shown, at least in studies in US, to play a crucial role. The public libraries are both based in communities and thereby embedded into local 
networks and they are carrying the competences of knowledge and information management for the public. A national survey on libraries and digital inclusion in the US concludes [18, p.134] that:

"...libraries, together with government agencies and community organizations, are increasingly recognizing the need for collaboration to better address the needs of users"

However, in the Swedish context such collaboration through networked governance is a basic condition of the local government [19], as shown by the inclusion of regions and interests groups in this specific project. However, there is a lack of interaction, not just in this project, with private firms and services providers.

In addition, there is a need to step further into the understanding of citizens as users of these services provided through collaboration. There is a low understanding for the determinants of demand on digital services among citizens, since public digital services often are designed for an organisational perspective rather than the user [20,21]. Commonly users (citizens) are seen as potential adopters as the last link of chain of actors in the implementation process. Often, the result of such practical approaches lead to low adoption and use, and even more in the most marginalized groups of citizens. Helbig et.al. [16] also argue for the need to consider how public managers' assumptions about e-government and digital divide issues influence the design. Such a poor and often normalized understanding and modelling of who is the users is embedding several problems in processes of "demand driven development" [22]. Thus, Gidlund and Sefyrin [22] argue that design of public e-services has to be guided by an open-minded approach to the concept of user. In this study, we will thus follow their advice and try to look beyond the categories of users to get guidance for how to deal with digital inclusion. Such an approach is in line with more sociological and even anthropological approaches, making research open and all-inclusive [23]. This is complicated since we as researchers also have a notion of the right, or at least better, solutions. The board research on digital divides [1, 13] has shown that social divides in non-digital contexts are mirrored but also partly re-framed in digital contexts.

\section{A. A European policy on digital inclusion - Get Online Week/eCitizen's week}

There are several policy initiatives on European level to enhance participation in the digital society. A Digital Agenda was agreed upon in the European Parliament in 2010 [24] addressing among several other policy-challenges the digital divides. There is still a heavy focus on access, the "lowest" level of digital inclusion, but since it is lacking in several member states it has to be addressed on such a general level. But there are also more practical initiatives to promote digital inclusion.

The European campaign Get Online Week, which always is held the same week in the participating countries, has been arranged since 2010 in at least 34 countries and reached over 900000 Europeans [24]. These two campaigns are coordinated by a non-hierarchical network in Sweden, called Digidel, which is working for an increased digital inclusion in Sweden. In Sweden, there is a similar national campaign week called eCitizen's week which has its focus on e-services in general but also the digital divide between citizens. This national campaign week involves actors both on local, regional and national levels. The main purpose of this campaign is to increase the digital inclusion in Sweden. In 2016 the national campaign week reached, along with their 170 participating organisations, over 20000 inhabitants [24].

\section{CONTEXTUALIZING THE CASE STUDY - THE POLICY BACKGROUND}

Bertot et.al.[20] points at the importance of the libraries to implement e-government services in broad areas of public services such as seeking social services and unemployment benefits, renewing licenses, paying taxes, and applying for citizenship or a passport. In an advanced welfare state as the Swedish, this is even more important, since there are extensive public services that are mainly provided and delivered through digital channels.

In addition, the high level of immigrants in Europe and in Sweden in the last years has increased the pressure on public services and not at least on e-government systems for such services. These group has a weaker integration in both welfare services and the digital public spaces in their new country [19]. This project thus had a specific focus to reach out and include new citizens, and asylum seekers and.

The regions and the municipalities in Sweden, have as a main assignment to provide public health care to the inhabitants. There are also national agencies in different sectors evaluating all the local public services. There are general policies and legislation aiming that citizens all over the country should have the same services in spite of the local provision. This is a challenge for the local and regional municipalities, not at least due to economic constraints [c.f. 25, 26]. In the last twenty years or so, the main development in the local government management in Sweden is highly in line with NPM [27]. However, the library services, as in focus here, have not been outsourced nor under clear NPM management. However, inclusion in general in a society is crucial for public health and a key for the regions' welfare policies [28]. Inclusion, solidarity and affinity with the society are aspect of public health in Sweden since such aspects clearly correspond to physical and not at least psychological health [29]. Thus, digital inclusion becomes related also to more general regional policy aims. and illness prevention is thus an important policy area as well. There are several policy ambitions combined into the projects focusing on digital inclusion, even if Sweden ranks high on Internet usages in international comparisons.

In Sweden today, 93 percent of the population that uses the Internet. About 840000 people are still unable or unwilling to use the Internet; however, of them only 200000 , approximately $2 \%$ of the population expressed in the yearly governmental 
survey on Internet use, that do not want to use it [30, p. 109]. In 2011, the Swedish government presented a digital agenda for Sweden. The purpose of this agenda was clear, to gather all current activities into a coherent strategy to take advantage of all the opportunities that digitization offers people and businesses. The national digital agenda focus on digital inclusion and says that the usability of digital public services must increase [31]. In line with the national digital agenda, several regions have had a networked approach to form a similar agenda for the challenges their specific challenges. The Regional Digital Agenda of Östergötland includes five focus areas of which one of them is about digital literacy and participation. A specific focus for the period of 2014-2016 has been to increase digital inclusion with particular affirmation of asylum seekers and refugees that have come to the region during this period in a large number [32]. According to the Region's own statistical analysis 40000 people out of the 445661 in the region are not digitally included.

\section{A. The national library legislation}

The $1^{\text {st }}$ of January 2014 a new library law began to apply in Sweden. This new legislation has its focus on the developing of our democratic society and that all our citizens will have an equal competence in our digital society. It is paragraphs 2 and 7 which in particular promote digital literacy:

"§2 The libraries in the public library system shall promote the development of a democratic society by contributing to the transfer of knowledge and the free formation of opinions. The libraries in the public library system shall promote the status of literature and an interest in learning, information, education, and research as well as other cultural activities. Library activities shall be available to everyone."

l.../

"§7 Public libraries shall in particular promote reading and access to literature. Public libraries shall act to increase knowledge about how information technology can be used for the attainment of knowledge, learning, and participation in cultural life." [33].

These quotes are translated by the national library organization and point out that the libraries have a responsibility in their democratic mission to increase the general digital inclusion in the Swedish society. It is clear that the government considers libraries not just as an actor for digital inclusion within their traditional fields of books and information searching, but a larger assignment to all forms of digital public life.

According to the Swedish library law, every single municipality shall have a library that is open and available for all citizens and it is the municipalities who are responsibility for the public libraries [33]. The outcome of the work with digital inclusion thus differ between municipalities, due to the local autonomy, but they all have to address digital inclusion.

\section{DIGITAL MEDIA BUS IN ÖSTERGÖTLAND - THE CASE STUDY}

This paper has its focus on the project Digital media bus in Östergötland, that took place in the region of Östergötland in 2016. Here we present the activities at the project meetings, the study trip and finally the more in-depth participatory observation in Norrköping where the project was extended, when the municipal cultural committee decided to invest another 200000 SEK in the project and to make the library bus running the project on weekends to socio-economically disadvantaged districts in the municipality.

\section{A. Project meetings with all libraries and the disability federation in Östergötland}

In line with the project plan, funded by Vinnova, there were project meetings to share the experiences and focus on lessons learned by the project in the different municipalities. Since the libraries only collaborated sparsely, there was an appreciated need just to meet and discuss these specific issues and other general issues on library buses in the region. In total, there have been eight project meetings in 2016. The first project meetings discussed more generally how the project will continue to develop, whereas the latest meetings discussed the more precise and detailed design of the library buses of Motala and Norrköping and how to transform them into mobile media buses.

There were three subjects which the project group talked about nearly every meeting: the political order, the librarians competence, and how to interpret the meanings of digital inclusion as expressed in the library law. The political support of the project in the region and the participating municipalities was important, since the participants got an impression that the work done at the libraries was seen as important. At one of the meetings a librarian said:

"Through political orders, you can also get more people to know about what's happening in the library bus and other library activities. It opens up the eyes of the politicians!" [Observation note from project meeting 161116]

However, in spite of the general political support locally and in the national legislation, it was not always easy for the project members to translate to their daily work situation, as one of them expressed:

"How shall the librarians actually interpret and manage its democratic mission according to the library law? It is important and necessary to understand the values and to learn new things as a part of the democratic mission" [Observation note from project meeting, 161018]. 
A similar more open discussion came up on what is actually the assignment of the public libraries in the digital age:

"What role should the library bus actually have in an increasingly digitalized society? Should we collaborate with banks and use the library bus to go out and help citizens with banking? The library and the librarian's role is constantly evolving! It is important to keep up with the development of society and not be conservative."

Our comments: The project group expresses that there is too much focus on the librarian's own competence. They as librarians have to face activities and other things that are not included in their "regular" skills" and not at all what their education has included." [Observation note from project meeting, 161116].

The relation to the private bank system can be seen as odd, but there are links to public services and e-government. Most of the e-government services in Sweden are provided through an advanced electronic identification system provided by the private bank system $[34,35]$. Thus digitalization, and not at least digital inclusion, have to address these contacts to be able to support the citizens' usage of digitalized public services. The libraries have to include relation to actors far beyond their traditional assignments and contexts. This is probably a consequence of a more networked governance setting and the national decision of using banking systems for access to public services and in line with the NPM approach. The large amount of newly arrived immigrants that are lacking banking accounts was in a catch 22 in-between access to public services and the banks hesitation to give them accounts. The immigrants often ended up at the libraries with their problems since they considered the public library as an accessible place. This was rightly in line with the library law, but still not anything the libraries could address. However, it indicated the need for the public libraries to stretch out into new services for them and this was discussed frequently at the project meetings. Here the networked governance arrangement opened for new problems locally at libraries and other forms of exclusion not foreseen in the national legislation.

The participants in the project meeting agreed upon the importance to inform policy makers about the practical and structural problem that emerges through such digital divides. They mobilized on how to give feedback on these issues in each municipality and asked the region to raise the issues as well. The project group also meant that if the libraries are going to be the core in solving the issues about the digital divide, they have to both seek cooperation and be brave about working with some new areas. An opportunity, in the work with digital literacy, was to speak about it in democratic ways and be supported by the library law. This showed that the project meetings came to go far beyond the project plan and the media buses. The main outcome of the meetings was not the design of the buses, but rather the more complex interpretation of digital divides as it is expressed at the libraries. This is in line with the new roles that the libraries got assigned within the implementation of the internet in the society. Education in general and in particular on the use of public e-services can increase the society's digital inclusion, that in turs can improve legitimacy of government [21] and the importance of the public libraries [5, 18].

\section{B. The study trip to the region of Gävleborg}

To place the work in the project in a larger context, to get inspiration, and come together the project group, some invited guests went on a study trip to Gävleborg in April 2016. On the trip, there were 19 participants. 12 people were from eight different municipal libraries, three were from the regional library in Östergötland, one member of the municipal committee in Motala, two representatives from the disability federation in Östergötland, and one of us. During the bus trip, there was a group discussion on participation and integration held by the chairperson of the disability federation in Östergötland. The chief of Motala's library held a lecture about library bus service and told of a study trip to Finland, where they visited a library's bus which had as purpose to increase the use of the internet in socio-economic disadvantaged areas. In these ways, the participants in the project opened and included other perspectives.

A main lesson learned from the "Mobiblan" was how they work with digital literacy and their cooperation with organizations and a project initiated by the municipality of Sundsvall. One of the participants summarized it as:

"It is interesting how digital inclusion was combined with labour market policies. Here the library gave work training positions for people with different language skills. They had to guide information searching and teach about digital technology and public services in their own languages. This show how important it is with collaboration!"

Hereby, it also became obvious for the participants to see how the public libraries can act as a node for digital inclusion through an extensive collaboration in networks. Through networked governance several policy assignments, here labour market problem and digital inclusion, were integrated and addressed in collaboration.

When the project group visited the Culture House, which comprises several different culture actors including the public library and a digital learning centre, this need to combine and bridge over different organisational sectors became obvious. They presented their cross-media project called, Young Story Architects, combing dramaturgy with computer programming for young people. One of the aims of this project was to get more young women into the programming courses. They were addressing gender and age aspects of digital divides in a creative and successful way. The common house of culture includes many kinds of cultural, digital and technical activities and this seems to promote integration of people and ideas in new ways. This inspired the visitors from our project group. The participants from Östergötland appreciated these, and also identified other consequences, like: 
"Interesting to see the use of the word 'telling and creating' instead of 'programming'. This seems to have the result that more girls visit the culture house and learned how to program."

The project group agreed about that a common arena for different kinds of cultural activities was great because of the integration between people and activities. Hereby, the project group started to reflect upon several dimensions of digital divides and new forms of inclusion. The importance of bringing more openings for activities in the digital media bus became obvious for the project focus. Thus, these ideas inspired the sub-project in Norrköping in the autumn of 2016.

\section{Digital media bus in Norrköping - The in-depth case study}

In line with the national legislation the culture and leisure committee in Norrköping municipality had decided that the public library should take on a key role in the promotion of digital inclusion. The committee also put an emphasis in their decision on the cultural activities in two suburban areas with low socio-economic status. The public library had also an assignment address availability and put special efforts to disadvantaged groups from democratic and demographic points [36]. The culture and leisure committee had stated that integration from a democratic point of view is also about every citizen's, regardless of background, right to information and culture. Therefore, the library had to develop their availability both physically and conceptually to reach more and new groups of citizens more efficiently [36].

The public library in Norrköping, including their library bus, had in their own management plan chosen to primarily address children's needs. Through this project and the additional funding the library bus was during the weekends rearranged as a digital media bus aiming to increase the interest among children and the youth in digital and technical development. A main aim was to promote interest and increase the awareness in the target group by access to tools that could open new ideas and promote creativity. Thus, the library bus was equipped with technology like virtual reality glasses, a 3D printer, several programming languages, and iPads. In addition, the library had employed two university educated engineers from the media and technology program in Norrköping. They were at the moment unemployed and their salaries were funded through a labour market program. They had a background from Syria and the competence to teach about technologies even in other languages than Swedish. Thereby they could reach out better to the target group. Their main roles are to help the librarians with digital and technical competence and with language competences.

The tour of the library on Sundays was decided to focus on two suburban districts, called Hageby and Klockaretorpet. These are areas with low socio-economic standards and high level of newly arrived immigrants to Sweden. In Hageby, the library bus collaborated with the community centre Portalen. Portalen is a meeting place to support the citizens own capacity to manage challenges like studies, family life and getting access to the labour market. It became an arena for this project, since it could dock the media bus into exciting projects and networks of visitors. In Klockaretorpet the bus just stopped in a central area without any local support organisation.

On Saturdays the librarians, together with the engineers, worked with different kinds of digital and technical tools. The children visiting the bus were introduced to a programming language called Scratch. This is a "block programming language", where you can create your own interactive stories, games and animations. Scratch is also an online community, which allows the children to continue with their programming after the visit to the bus.

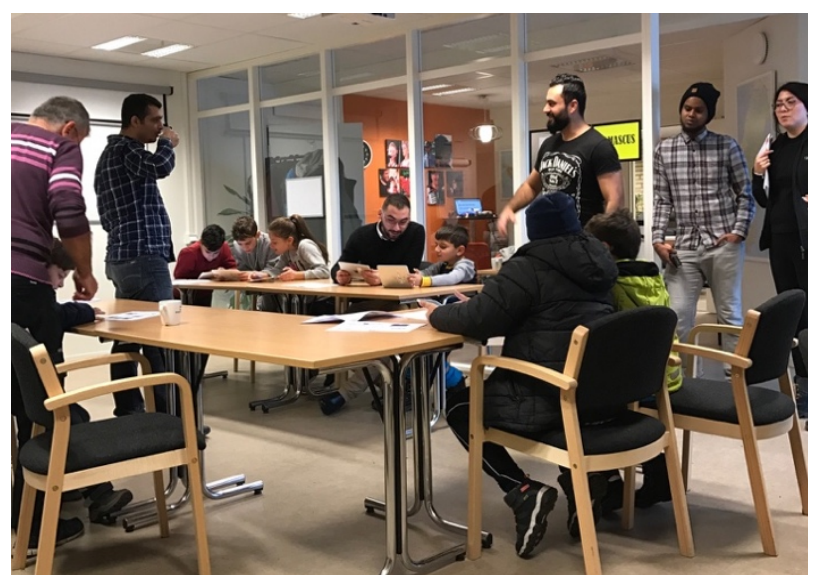

Figure 1. Snapshot from Portalen, children are learning Scratch

There were a lot of activities going on when the bus visited these suburbs. At Portalen the ordinary visitors were engaged and included in the media bus projects. The staff at Portalen, including teachers and librarian, had prepared the visit and encouraged people to come, mainly on their web page and by posters. They even had a Facebook page that they used for such invitations.

The children also got the opportunity to work with a toolkit called MakeyMakey. It is an electric tool and toy that allows users to connect everyday objects to computer programs. The main purpose of MakeyMakey is to let everyone try to make a simple program and be creative and innovative.

At one Saturday, we made these notes during the visit:

"The engineers from Syria does a great job. They have been a helping hand on all activities on the library bus in this project. The librarians have much trust in them. If the library will continue to work with issues on digital literacy and inclusion, it is important that they have digital and technical base skills (and an interest!), if they are going to manage this themselves. Without the engineers, the children would not have gotten so many right answers and help, because the librarians could not answer all the questions." [Observation note from the bus activities in Hageby and Portalen, 161112]. 
This quote was referring to the importance with cooperation in the work with increased digital inclusion. The public library plays an important role in bridging digital divides, but the librarians cannot have all the competences which an increased digital inclusion requires. Therefore, it is necessary to find relevant partner to cooperate with.

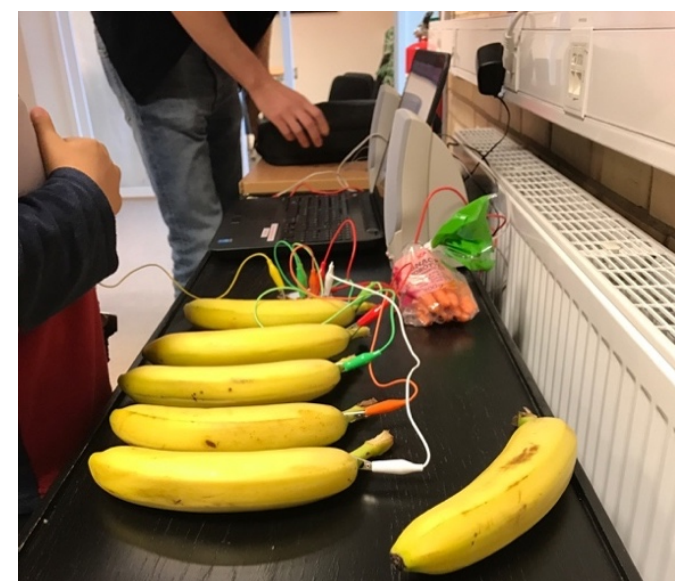

Figure 2. Snapshot from Portalen, MakeyMakey with bananas

Together with the engineers, the librarians also introduced the children with tools like a 3D printer, LEGO Mindstorms and Virtual Reality Glasses. There were visitors mainly looking for books but they also got introduced to the digital media applications and discussed it. In Hageby fewer visitors to the library bus were familiar with the project and came more to look for the ordinary library services. The staff than discussed in terms of looking for new ways to get contacts and invite participants. One of the staff in Hageby reflected by the end of the first Saturday visit by saying:

"Maybe it is necessary in a project like this to seek cooperation with established organizations in the residential districts. It seems to be harder for people to get in the library bus, whereas it seems rather simple to visit an established organization like Portalen." [Interview with staff at the bus activities in Klockaretorpet, 161029].

The groups of visitors to Portalen were usually young people and children. Children are most often accompanied by their parents or care-takers. This was the case also at these occasions. We noticed the importance of this support in the field notes:

"Today's focus was on the children and to increase their digital literacy. But the project team should also have been more preprared to address and include the parents and other adults that came together with the children." [Observation note from the bus activities in Hageby and Portalen 161015].

The project developed positively. When the bus was visiting Klockaretorpet for the third time, children were waiting and came into the library bus almost immediately. This was in contrast to the first visit when there were less children and those who came were quite sceptical against the bus. This indicates the importance to have patience in project like this, there is no immediate change. Activities and projects like these are needing a good reputation amongst the target groups. So, there is a good prospect for further development and more inclusive activities. However, since this was a limited project and the funding ended after just a few Saturday visits, there are risks that the long-term impacts are missing out.

\section{Focus group feedback - Final seminar at the library in Norrköping}

The project was concluded at a common seminar in December 2016 at the public library in Norrköping. There had been an open invitation for the seminar and participants from participating libraries, members of the executive committee of the municipality in Norrköping as well as librarians from other regions showed up. The aim of the seminar, according to the invitation, was to discuss the opportunities that with digital tools - like social media, web services and other forms of information technology - increase citizen participation in society, their competence, and develop our local democracy. The seminar was organized as an interactive focus group interview

The seminar aimed to talk about the project Digital Media Bus, digital inclusion and why it is important and necessary to talk about. Four questions were in focus for the discussion through the seminar:

- How do we build our society with digital tools?

- Can a municipality work for an increased digital inclusion? How?

- What was the main experiences of the project Digital Media Bus?

- How do we proceed to increase our region's digital inclusion?

Two of the members of the municipal executive committee in Norrköping took active part in the seminar and thereby they pointed out the political importance of these issues. They also highlighted the importance of the digital divide, as a democratic question which needs attention and must be drawn on the political map. The politicians argued that this question, about the digital divide, must be seen in other forms rather than just the technical infrastructure. They rather pointed at more social and political problems [2] and how these are related to public health and as a general base of an inclusive and sustainable society where all citizens and new comers are included [28, 29].

They discussed in terms of integrating digital inclusion in more services by the end of the seminar. But they also pointed at the problems generated by the silo-organization of local public administration, that they considered as a main constraint for the library to reach into other public services as schools, elderly care and social services.

Another outcome of the seminar were the discussions on how the library can reach more people through a project like this. The project in Norrköping had showed that only few citizens were reached by invitation and had taken the time to come. Thus, the project may not be the best way to reach out to new groups. The participants from the municipality of Motala, which is a 
much smaller municipality than Norrköping's municipality, said that similar challenges had been a problem in their attempts to reach new groups with a digital media bus. But they had reached more people, even though they are a smaller municipality. Their focus had mainly been on the visitors more personal digital problems and the use of digital public services. Thus, they had people asking for help with practical things as searching the web, connecting to their electronic medical patient records and similar things, as in line with the American studies of Bertot et.al. $[4,14]$. This may be a result of the more open approach without any specific technology like the 3D-printer and the programs for children, as they had focused in Norrköping.

\section{DIGITAL DIVERSITY - CONCLUDING REMARKS AND FURTHER RESEARCH}

The main implications of this project is that there is a need to address digital inclusion in many different ways and be aware of the needs in the target group. It was easy to get in contact with the children, when playing and building with digital tools were in focus. The digital media bus also provided openings to include parents and caretakers more actively since it was a specific activity outside school. There are potentials to extend such activities and use the children's interest to involve others. However, it was clear that if the project had stretched over a longer time the impact would have increased. When aiming at groups of people speaking other languages it was also a great advantage to include staff with competences to talk about the digital technology in other languages. The policy implications of the project were, overall, positive. The engagement from the members of the executive committee at the final seminar, is a good sign of the importance and relevance of the project. It also pointed out how problematic it is for policy makers to address such integrative policy aims as digital inclusion.

The digital divide is a common problem that transcends multiple areas in society. To address such broad problems network governance is a common strategy to create opportunities for different actors and organizations to create solutions together. In the US, where they have worked with library buses to reach out to disadvantaged youths, cooperation in broad terms has been found to be a critical factor. Also, there they used established meeting places to reach more youths and because of the youth's own safety - the buses go to places were the youths are secure and confident [14]. It can be difficult for different target groups to visit the library bus because of its "stamp" to be a library bus. Many do not have the knowledge about the libraries education mission, which can make it hard for the library buses to get visitors. But with cooperation together with established meeting places, they would probably reach more people.

There are today so many ways to connect to digital services and applications that we have to have an openness to the drivers use of technology. If basic technology and infrastructure is there [13] we still have to look for more intriguing ways to use the technology and to connect in different ways. It is also clear that there is a massive amount of technological diversity including different tools, not at least as shown by the use at the library buses for children. There has been an openness to see digital competences in different ways. The approach by using MakeyMakey at the digital media bus was to introduce programming and design of technology for children. But this may be seen by their parents as if they were digitally excluded since they did not understand the MakeyMakey. This was not our ambition. But the impression could have been that you need to know programming to be included. Thus, we have to consider the diversity of technological and social competences.

In a Swedish context, this project has also given us a broader understanding for the library's mission. They have a legislation they must follow [33], which creates a space for the libraries to be a natural arena for questions about digital divides and diversity. Research has shown that the libraries play an important role when increasing the digital inclusion in the society. They have it in their mission, they are educational, and they reach all people, independent of background and conditions.

Thus, the overall conclusion drawn is that instead of focusing on digital divides we would like to elaborate on the digital diversities in society. Hereby, we will in particular point at the many different ways citizens can be included in a society. A more general lesson learned from the project is that we may have to open the meanings of digital divides to look more for different ways of getting inclusion by embracing different ways to approach digital technologies and services. This might be the meaning of digital diversity rather than digital divides. From a diversity perspective [8], we also have to include and consider the diversity of needs among citizens and different target groups. The NPM context of public services is enforcing individuality and diversity of service providers, that has to be met also when it comes to digital inclusion. But citizens have diverse competence of understanding public administration and what is offered, their rights, and duties. Thus, there is a need for even more diversity in the public digital services and ambitions for inclusion in such fields.

This case study open both for a more elaborated understanding of the library in the digital era. We have also through the action oriented approach seen the importance of finding new ideas and approaches in research through an open-minded collaboration in projects including research and social change. Thus, we see a need for more collaboration and not at least for a more intrigued elaboration on the meanings of digital inclusion.

\section{ACKNOWLEDGMENT}

This project has partly been funded by the Swedish Innovation Agency Vinnova, grant number 2016-000379, the Region of Östergötland and additional faculty funding from Linköping university. 
[1] P. Norris, "Digital divide: Civic engagement, information poverty, and the Internet worldwide." Cambridge University Press, 2001.

[2] J. van Dijk, "Digital divide research, achievements and shortcomings." Poetics 34.4-5 (2006): 221-235.

[3] M. Ragnedda, and G. Muschert (eds). The digital divide: The Internet and social inequality in international perspective, Routledge, 2013.

[4] J.C. Bertot, P.T. Jaeger, U. Gorham, N.G. Taylor, and R. Lincoln, "Delivering e-government services and transforming communities through innovative partnerships: Public libraries, government agencies, and community organizations." Information Polity, 18, 127-138, 2013.

[5] J.C. Bertot, C.R. McClure and P.T. Jaeger, "The impacts of free public Internet access on public library patrons and communities", Library Quarterly 78, 2008, 285-301, 2008.

[6] https://peterals.wordpress.com/category/den-digitala-klyftan/

[7] Statistics from the Royal (national) library of Sweden, http://biblioteksstatistik.blogg.kb.se/files/2016/05/Tabeller Bibliotek 2015.xlsx, and The National Library Organisation, "Promoting the development of a democratic society", http://www.biblioteksforeningen.org/wpcontent/uploads/2016/04/Development-of-of-a-democratic-society.pdf

[8] E. Wihlborg, K. Hedström \& H. Larsson, "e-government for all! Norm-critical perspectives and public values in digitalization", Proceedings of the $50^{\text {th }}$ Hawaii International Conference on System Sciences, 2017.

[9] E. Gunnarsson, et al., Action Research for Democracy: New Ideas and Perspectives from Scandinavia, Routledge, 2015.

[10] U. Melin, and K. Axelsson, "Action in Action Research-Illustrations of What, Who, Why, Where, and When from an E-Government Project." International Conference on Electronic Government, Springer Berlin Heidelberg, 2007.

[11] M.T. Gustafsson, and L. Johannnesson (eds.), Introduction to political ethnography [Introduktion till politisk etnografi.” Malmö: Gleerups förlag, 2016.

[12] S. Holmlid, "Participative; co-operative; emancipatory: From participatory design to service design." Conference Proceedings ServDes. 2009; DeThinking Service; ReThinking Design; Oslo Norway 24-26 November 2009. No. 059. Linköping University Electronic Press, 2012.

[13] S. Park, "Digital inequalities in rural Australia: A double jeopardy of remoteness and social exclusion", Journal of Rural Studies, 2016. [14] K.M. Thompson, Jaeger, P. T., Taylor, N. G., Subramaniam, M., \& Bertot, J. C., Digital literacy and digital inclusion: Information policy and the public library, Rowman \& Littlefield, 2014.

[15] P.T. Jaeger, and J.C. Bertot, "E-government education in public libraries: New service roles and expanding social responsibilities." Journal of Education for Library and Information Science, 50, 39-49, 2009.

[16] N. Helbig, J.R. Gil-Garcia, and E. Ferro, "Understanding the complexity of electronic government: Implications from the digital divide literature", Government Information Quarterly, 26(1), pp. 89-97, 2009.

[17] J.C. Bertot, "The multiple dimensions of the digital divide: More than the technology 'haves' and 'have nots'." Government Information Quarterly 20.2: 185-191, 2003.

[18] J.C. Bertot, J. C., Jaeger, P. T., Gorham, U., Taylor, N. G., \& Lincoln, R., "Delivering e-government services and transforming communities through innovative partnerships: Public libraries, government agencies, and community organizations" Information Polity, $18(2), 127-138,2013$.

[19] G. Lidén, "Inequality in Local Digital Politics: How Different Preconditions for Citizen Engagement Can Be Explained" Policy \& Internet (8), 270-291, 2016.

[20] Bertot, John Carlo, Paul T. Jaeger, and Charles R. McClure. "Citizen-centered e-government services: benefits, costs, and research needs." Proceedings of the 2008 international conference on Digital government research, 2008.

[21] Wihlborg, Elin. "Legitimate E-Government--Public E-Services as a Facilitator of Political Legitimacy" $47^{\text {th }}$ Hawaii International Conference on System Sciences, IEEE, 2014.

[22] K.L. Gidlund and J. Sefyrin, Problematizing the Participatory Subject in Demands Driven Development of Public Sector, in Electronic Government and Electronic Participation, M. Janssen, Ed. 2014.

[23] L.H. Moore, A passion for difference: Essays in anthropology and gender. Indiana University Press, 1994.

[24] The DigiDel Network, "Other languages" http://digidel.se/other-languages/ and The DigiDel Network, "Get Online Week 2017", http://digidel.se/gow17-2/ access: 2016-11-27.

[25] Swedish Code of Legislation, SFS 1990:900, The Municipal Act, [Kommunallagen].

[26] M. Granberg, "Local governance 'in Swedish'? Globalisation, local welfare government and beyond.” Local Government Studies, 34(3), 363-377, 2008.

[27] H. Wollmann, "Local government reforms: between multifunction and single-purpose organizations", Local Government Studies, 42, 3 , 2016.

[28] M. Elg, J. Lindmark, M. Wiger, and E. Wihlborg, Translating guideines: Case studies of methods for illness preventions ["Översättning av riktlinjer: Fallstudier av sjukdomsförebyggande metoders genomslag."] Linköping: Linköping University e-press, 2016.

[29] K. Liljeberg, "Hur påverkas hälsan av delaktighet och inflytande i samhället? En litteratursammanställning." Stockholm: Statens folkhälsoinstitut, 2005. The Public Health Agency of Sweden, "Participation and influence in the society" "Delaktighet och inflytande i samhället”, https://www.folkhalsomyndigheten.se/pagefiles/12709/R2011-31-Delaktighet-och-inflytande-i-samhallet-Kunskapsunderlagfor-FHPR-2010.pdf

[30] O. Finndahl, "The Swedish and the internet 2016", 2016.

[31] The region of Östergötland, "Digital agenda for Östergötland $2014 \quad>\quad 2020$ ", http://www.lansstyrelsen.se/ostergotland/SiteCollectionDocuments/Sv/samhallsplanering-och-kulturmiljo/infrastruktur-ochit/bredband/Digital agenda för Östergötland 2014-2020.pdf

[32] M. Gustafsson, "Digitalization and the Challenge of Engagement in New Forms of Governance: A case study on adoption and implementation of the Regional Digital Agenda for Östergötland, Sweden.” Presented at The European Group for Public Administration (EGPA) Annual Conference, Toulouse, 26-28 August, 2015. 
[33] The Swedish national Library legislation (SFS 2013: 801), accessible in English at: http:/www.biblioteksforeningen.org/wpcontent/uploads/2016/04/Development-of-of-a-democratic-society.pdf

[34] E. Wihlborg, "Secure electronic identification (eID) in the intersection of politics and technology.", International Journal of Electronic Governance, 6 (2), 143-151, 2013.

[35] U. Melin, K. Axelsson, and F. Söderström, "Managing the development of e-ID in a public e-service context: Challenges and path dependencies from a life-cycle perspective." Transforming Government: People, Process and Policy, 10(1), 72-98, 2016.

[36] The municipality of Norrköping, "Culture and leisure committee's assignment plan" http://www.norrkoping.se/organisation/pdf/malregler/uppdragsplaner/kultur/kultur-fritidsnamnden.pdf.

Norrköpings municipality. Yearly plan for 2016 by the cultural committee, avalible at: http://www.norrkoping.se/organisation/pdf/malregler/uppdragsplaner/kultur/kultur-fritidsnamnden.pdf 